\title{
An Integrated EPLOS Database as a Tool Supporting TSL Companies
}

\author{
Mariusz Wasiak*, Michał Kłodawski, Konrad Lewczuk, Piotr Klimek, Emilian Szczepański
}

\begin{abstract}
The paper presents the conceptual design of a database for the European Portal of Logistics Services (EPLOS) and its application. The database contains the data on logistics companies, the infrastructure for road, railway, inland, and air transport, as well as the data on the nodal elements of logistics infrastructure (warehouse facilities, seaports, transhipment terminals). Complete and verified information is the fundamental condition for rational decisions about the realization of logistics processes on a meso- and macroeconomic scale. Authors present the relations in the making of the EPLOS database, its assumed scope, and the potential benefits for the TSL market from accessing the EPLOS database.
\end{abstract}

Keywords: EPLOS; European Portal of Logistics Services; integrated database; logistic data; parameters of a transport network

\section{INTRODUCTION}

Logistics services require many complex decisionmaking processes to be efficient and reliable. This is especially true for the configuration of long-distance freight transport and global logistics chains. Logistics processes use extensive and dispersed information for functioning. When valid and complete operational data are difficult to access, there can be a reason for an irrational logistics service. This problem is particularly acute for small and medium companies which do not invest in the decision support and data gathering systems tailored to their needs. Practice and research show that the bodies of this type dig for logistics information completely or partly manually, and that they use established contacts with no broad view on the market. This made a niche for a new IT system which would gather all or almost all information required for the bodies on the TSL market. The key element of this system is an integrated relational database.

The purpose of this paper is to discuss the concept of an integrated EPLOS database meeting the need for information on logistic entities and facilities, as well as their servicing potential and technical infrastructure availability, reported by the TSL market participants. The paper also describes the process of data gathering from functioning databases and other sources which feed the EPLOS system database.

The European Portal of Logistics Services (EPLOS) is developed under the EUREKA program by the National Centre for Research and Development (Poland). It is a comprehensive IT tool that supports the participants of the TSL market with access to verified information about the logistics infrastructure and services in the area of their operation. EPLOS users are not only the consumers of information, but also the source of information for other clients. This is done to reduce the time-consuming manual search and verification of operational data and to guarantee quick access to the reliable information uploaded in real time. This tool will be crucial for the planning of logistics and business processes, and it will help multi-organizational supply chains in the combining of different businesses in different countries.

\section{DATABASE DEVELOPMENT SOLUTIONS FOR LOGISTICS-RELATED APPLICATIONS}

The problem of designing a database for the European Portal of Logistics Services is similar to those presented in the studies [1-9]. It can be decomposed to two elements:

- database architecture (software development),

- EPLOS application (structure of business data).

Considering the following aspects of software engineering, database architecture designing requires the following [10-18]:

- a database model specified as a set of rules describing the structure of data in a database and a set of operations performed on data to process them as required. Typical database models are hierarchical, relational, network, object, and semantic. Particular types of models have advantages and disadvantages from the EPLOS point of view, but relational database is the first choice. The basic characteristic of a relational structure is that relationships between records are represented only by data values. Operational data are stored in tables interrelated by mathematical relations. The access to data is quick and the specific knowledge on database structure is not necessary to find specific information.

- a database schema presented as a graphical mapping of the database model (e.g. groups of tables, tables, headers of columns and relations),

- a database management system, a tool enabling developers to prepare the database for a specific system and to manage the entered data (adding and removing records, editing, modifying, sorting and other) [19, 20],

- algorithms and methods to maintain a high quality of the data described as a set of rules allowing to keep the consistency, accuracy, timeliness and correctness of the data and the database itself, as well as ensuring high effectiveness of its operation [20],

- a database structure given by the arrays of uniform data and the connections between these arrays made by mutual relations: one to one (one element from the array can be combined exactly with one element from the 
other array), one to many (one element from one array can be combined with many elements from the other array) or many to many (many elements from one array can be combined with many elements from the second array),

- database implementation and development with the IT tools based on the selected solutions from the abovementioned [21].

The programming work on the implementation of a database and the tools for database management are not discussed in this paper. Authors focus on database structure conceptualization and the references to the external data sources feeding EPLOS.

\section{REQUIRED FUNCTIONALITIES OF AN INTEGRATED EPLOS DATABASE}

A dedicated survey was designed and carried out to recognize the scope, form and relevance of the information required by different logistics businesses. The survey was also designed to recognize how the analysed companies obtain information and what their expectations in that matter are. The target group of EPLOS users is mainly composed of transport, forwarding, transhipment and warehousing companies using the means of transport with a total weight exceeding $3.5 \mathrm{t}$. The group also contains the representatives of service, production, and trade companies which are the points of origin or of dropping the goods.

The survey helped identify the types and economic size of the analysed bodies, their needs and the scope of the provided services. The respondents were examined for the timeliness and completeness of the information on transport infrastructure and different services related to this infrastructure, warehousing services, logistics centres and the transhipment terminals that they use.
The selection criteria for enterprises were defined through the expert method. Selection was based on the knowledge and experience of academics engaged in research on logistics matters and representatives of international enterprises supplying different classes of IT systems to logistics companies. Contact details of companies participating in the survey were gathered from their business websites and commercial databases. It should be noted that the highest percentage of responses was from the companies cooperating with the EPLOS project leader - the OLTIS company. Additionally, in view of the difficulties with obtaining representative samples of companies that are similar in terms of their economic size or scope of activity, it was decided that all completed surveys will be used for further research.

In total, 519 companies took part in the survey. The largest group were those employing 10 to 19 people $(30.1 \%$ of surveyed companies) and 20 to 49 people $(27.4 \%$ of surveyed companies). A group of respondents included: providers of logistics services $(28.71 \%)$, transport companies (43.74\%), infrastructure operators $(3.66 \%)$, development companies $(2.89 \%)$, manufacturing companies $(9.25 \%)$, trading companies $(7.32 \%)$, service companies $(2.7 \%)$, and media representatives $(1.54 \%)$.

The survey focused on the significance of the specific types of data for logistics companies. The following categories of data were subjected to importance evaluation:

- various types of information about the technical infrastructure of transport,

- various types of information about transhipment terminals,

- various types of information about warehouse facilities,

- parameters of the technical transport infrastructure,

- the servicing potential of facilities providing auxiliary logistics services.

The results of the survey, categorized by the types of services, are summarized in Tabs. 1 - 5 .

Table 1 Relevance of logistics infrastructure data for the participants of the TSL market by the type of services they provide

\begin{tabular}{|c|c|c|c|c|c|c|c|c|}
\hline \multirow{3}{*}{$\begin{array}{l}\text { Infrastructure parameter } \\
\text { type }\end{array}$} & \multicolumn{8}{|c|}{ Types of services offered by the company } \\
\hline & $\begin{array}{c}\text { In total } \\
(n=276)\end{array}$ & $\begin{array}{l}\text { Road transport } \\
(n=210)\end{array}$ & $\begin{array}{l}\text { Rail transport } \\
\quad(n=26)\end{array}$ & $\begin{array}{l}\text { Sea transport } \\
(n=21)\end{array}$ & $\begin{array}{l}\text { ADR transport } \\
(n=57)\end{array}$ & $\begin{array}{l}\text { ATP transport } \\
(n=21)\end{array}$ & $\begin{array}{c}\text { Forwarding } \\
(n=107)\end{array}$ & $\begin{array}{c}\text { Warehousing } \\
(n=30)\end{array}$ \\
\hline & \multicolumn{8}{|c|}{ Parameter importance in percentage } \\
\hline Parameters & 85.2 & 98.8 & 93.1 & 83.3 & 98.4 & 100.0 & 94.4 & 84.5 \\
\hline Services & 81.7 & 97.9 & 69.0 & 80.0 & 95.2 & 100.0 & 92.9 & 83.1 \\
\hline Fees & 84.8 & 98.8 & 89.7 & 86.7 & 98.4 & 100.0 & 96.4 & 85.9 \\
\hline Traffic restrictions & 87.5 & 100.0 & 100.0 & 100.0 & 100.0 & 100.0 & 99.0 & 91.5 \\
\hline Traffic volume & 86.5 & 98.3 & 89.7 & 90.0 & 95.2 & 95.7 & 97.0 & 88.7 \\
\hline
\end{tabular}

Table 2 Relevance of transhipment terminal data for the participants of the TSL market by the type of services they provide

\begin{tabular}{|c|c|c|c|c|c|c|c|c|}
\hline \multirow{3}{*}{ Terminal parameter type } & \multicolumn{8}{|c|}{ Types of services offered by the company } \\
\hline & $\begin{array}{c}\text { In total } \\
(n=276)\end{array}$ & $\begin{array}{l}\text { Road transport } \\
(n=210)\end{array}$ & $\begin{array}{c}\text { Rail transport } \\
(n=26)\end{array}$ & $\begin{array}{l}\text { Sea transport } \\
(n=21)\end{array}$ & $\begin{array}{c}\text { ADR transport } \\
(n=57)\end{array}$ & $\begin{array}{c}\text { ATP transport } \\
(n=21)\end{array}$ & $\begin{array}{c}\text { Forwarding } \\
(n=107)\end{array}$ & $\begin{array}{c}\text { Warehousing } \\
(n=30)\end{array}$ \\
\hline & \multicolumn{8}{|c|}{ Parameter importance in percentage } \\
\hline Owner & 73.4 & 63.3 & 96.6 & 100.0 & 77.8 & 73.9 & 89.8 & 80.3 \\
\hline Type & 73.4 & 65.0 & 96.6 & 100.0 & 73.0 & 65.2 & 90.4 & 83.1 \\
\hline Equipment & 66.3 & 55.4 & 96.6 & 100.0 & 61.9 & 56.5 & 83.2 & 80.3 \\
\hline Scope of services & 68.8 & 53.8 & 93.1 & 100.0 & 60.3 & 56.5 & 90.9 & 85.9 \\
\hline Operational capability & 75.7 & 72.1 & 89.7 & 96.7 & 77.8 & 73.9 & 91.9 & 84.5 \\
\hline Restrictions on access & 81.1 & 82.5 & 96.6 & 100.0 & 88.9 & 78.3 & 96.4 & 84.5 \\
\hline
\end{tabular}


Since the European Portal of Logistics Services is a tool dedicated to the companies from the TSL sector mainly engaged in transport and forwarding, the obtained results show that the EPLOS database should contain information on:

- charges for using the infrastructure,

- traffic restrictions and the current traffic situation,

- technical parameters of the infrastructure, including speed limits, permissible axle loads on the road, total weight and permissible gross weight limits, restrictions for ADR vehicles, vertical gauge limits, allowable length and gross weight of trains and limitations of the horizontal gauge (for railway lines), navigability classes;

- infrastructure services, including gas stations, car washes, guarded parking lots, unguarded parking lots, ports;

- transhipment terminals, including access restrictions, operating ability and throughput, terminal type, owner, equipment, scope of offered services;

- warehouse facilities, including access restrictions, additional services, owner, scope of offered services, equipment, surface, custom services.

Table 3 Relevance of warehouse facilities data for the participants of the TSL market by the type of services they provide

\begin{tabular}{|c|c|c|c|c|c|c|c|c|}
\hline \multirow{3}{*}{$\begin{array}{c}\text { Warehouse parameter } \\
\text { type }\end{array}$} & \multicolumn{8}{|c|}{ Types of services offered by the company } \\
\hline & $\begin{array}{l}\text { In total } \\
(n=276)\end{array}$ & $\begin{array}{l}\text { Road transport } \\
\quad(n=210)\end{array}$ & $\begin{array}{l}\text { Rail transport } \\
(n=26)\end{array}$ & $\begin{array}{c}\text { Sea transport } \\
(n=21)\end{array}$ & $\begin{array}{c}\text { ADR transport } \\
(n=57)\end{array}$ & $\begin{array}{l}\text { ATP transport } \\
(n=21)\end{array}$ & $\begin{array}{c}\text { Forwarding } \\
(n=107)\end{array}$ & $\begin{array}{c}\text { Warehousing } \\
(n=30)\end{array}$ \\
\hline & \multicolumn{8}{|c|}{ Parameter importance in percentage } \\
\hline Owner & 78.0 & 70.0 & 72.4 & 90.0 & 81.0 & 87.0 & 91.9 & 91.5 \\
\hline Area & 50.9 & 29.6 & 62.1 & 70.0 & 33.3 & 26.1 & 62.9 & 84.5 \\
\hline Equipment & 60.3 & 42.1 & 72.4 & 90.0 & 42.9 & 39.1 & 77.2 & 90.1 \\
\hline Scope of services & 65.9 & 45.8 & 69.0 & 93.3 & 54.0 & 47.8 & 90.9 & 93.0 \\
\hline Additional services & 84.0 & 85.8 & 62.1 & 86.7 & 87.3 & 95.7 & 93.9 & 90.1 \\
\hline Restrictions on access & 85.2 & 86.7 & 72.4 & 93.3 & 93.7 & 100.0 & 96.4 & 94.4 \\
\hline
\end{tabular}

Table 4 Relevance of linear infrastructure data for the participants of the TSL market by the type of services they provide

\begin{tabular}{|c|c|c|c|c|c|c|c|c|}
\hline \multirow{3}{*}{$\begin{array}{c}\text { Linear infrastructure parameter } \\
\text { type }\end{array}$} & \multicolumn{8}{|c|}{ Types of services offered by the company } \\
\hline & $\begin{array}{l}\text { In total } \\
(n=276)\end{array}$ & $\begin{array}{c}\text { Road transport } \\
(n=210)\end{array}$ & $\begin{array}{l}\text { Rail transport } \\
(n=26)\end{array}$ & $\begin{array}{l}\text { Sea transport } \\
(n=21)\end{array}$ & $\begin{array}{c}\text { ADR transport } \\
(n=57)\end{array}$ & $\begin{array}{c}\text { ATP transport } \\
(n=21)\end{array}$ & $\begin{array}{c}\text { Forwarding } \\
(n=107)\end{array}$ & $\begin{array}{c}\text { Warehousing } \\
(n=30)\end{array}$ \\
\hline & \multicolumn{8}{|c|}{ Parameter importance in percentage } \\
\hline Speed limits & 87.00 & 93.30 & 53.80 & 61.90 & 87.70 & 85.70 & 86.00 & 80.00 \\
\hline Limits of axle loads on the road & 73.90 & 78.10 & 69.20 & 81.00 & 75.40 & 71.40 & 80.40 & 80.00 \\
\hline $\begin{array}{l}\text { Total weight limits and } \\
\text { permissible gross weight }\end{array}$ & 38.80 & 36.70 & 65.40 & 81.00 & 42.10 & 28.60 & 51.40 & 63.30 \\
\hline Vertical gauge limits & 26.10 & 22.40 & 76.90 & 57.10 & 33.30 & 23.80 & 32.70 & 53.30 \\
\hline Horizontal gauge restrictions & 13.40 & 6.70 & 76.90 & 42.90 & 3.50 & 0.00 & 17.80 & 23.30 \\
\hline Restrictions for ADR vehicles & 56.50 & 61.90 & 50.00 & 66.70 & 77.20 & 33.30 & 66.40 & 76.70 \\
\hline Longitudinal inclination of roads & 6.90 & 5.70 & 34.60 & 33.30 & 0.00 & 0.00 & 14.00 & 20.00 \\
\hline Train length limits & 15.60 & 6.20 & 76.90 & 42.90 & 1.80 & 0.00 & 16.80 & 23.30 \\
\hline Trains' gross mass limits & 14.10 & 5.70 & 76.90 & 42.90 & 1.80 & 0.00 & 15.00 & 23.30 \\
\hline Navigability classes of waterways & 2.90 & 1.40 & 15.40 & 14.30 & 5.30 & 0.00 & 4.70 & 3.30 \\
\hline
\end{tabular}

Table 5 Key or important information about the facilities integrated into the linear transport infrastructure by the type of services they provide

Table 5 Key or important information about the facilities integrated into the linear transport infrastructure by the type of services they provide
\begin{tabular}{|l|c|c|c|c|c|c|c|c|}
\hline \multirow{2}{*}{$\begin{array}{c}\text { Type of facility integrated } \\
\text { into the infrastructure }\end{array}$} & $\begin{array}{c}\text { In total } \\
(n=276)\end{array}$ & $\begin{array}{c}\text { Road transport } \\
(n=210)\end{array}$ & $\begin{array}{c}\text { Rail transport } \\
(n=26)\end{array}$ & $\begin{array}{c}\text { Sea transport } \\
(n=21)\end{array}$ & $\begin{array}{c}\text { ADR transport } \\
(n=57)\end{array}$ & $\begin{array}{c}\text { ATP transport } \\
(n=21)\end{array}$ & $\begin{array}{c}\text { Forwarding } \\
(n=107)\end{array}$ & $\begin{array}{c}\text { Warehousing } \\
(n=30)\end{array}$ \\
\cline { 2 - 9 } & \multicolumn{7}{|c|}{ Parameter importance in percentage } \\
\hline Gas stations & 90.00 & 94.30 & 56.30 & 55.00 & 96.60 & 95.20 & 86.90 & 78.00 \\
\hline Car washes & 76.30 & 80.60 & 43.80 & 45.00 & 82.80 & 90.50 & 77.90 & 63.40 \\
\hline Unguarded parking lots & 76.30 & 84.10 & 50.00 & 55.00 & 87.90 & 76.20 & 73.80 & 68.30 \\
\hline Guarded parking lots. & 93.80 & 98.20 & 68.80 & 85.00 & 100.00 & 100.00 & 93.80 & 87.80 \\
\hline Ports & 41.10 & 37.00 & 62.50 & 45.00 & 37.90 & 42.90 & 49.70 & 46.30 \\
\hline Hotels & 18.10 & 19.40 & 12.50 & 10.00 & 27.60 & 14.30 & 11.00 & 9.80 \\
\hline Gastronomy & 10.00 & 11.00 & 0.00 & 5.00 & 13.80 & 0.00 & 4.80 & 0.00 \\
\hline
\end{tabular}

\section{THE CONCEPT OF THE EPLOS INTEGRATED DATABASE}

The EPLOS system created under the EUREKA initiative is a database tool providing information on the transport and logistics infrastructure and other services from logistics companies (by the WebServices) to the business. The target group of EPLOS users are primarily small and medium logistics and transport companies (which only plan the realization of their services), but also production and distribution companies (which not only plan their services, but also design supply networks and supply processes).
Through WebServices, the EPLOS system will provide verified and valid logistics data to interested companies in a form required by their specialized IT systems. This will facilitate and accelerate further processing of this data and will later allow those companies to upload data back to EPLOS. The data from EPLOS can also be used by research units and universities in order to develop and test data processing algorithms supporting the strategic and operational logistics decision-making. In the next stages of development, EPLOS will be extended with data analysis tools and logistics decision supporting. After that, the EPLOS 
system will gain additional functionalities which will cause a significant increase of data in the system.

The EPLOS database must contain extensive data grouped into different thematic areas. These thematic areas make a complex and differentiated structure, which is why the methods of data gathering, along with the data sources, must also be diversified. Therefore, the EPLOS database is updated with business and technical data from different sources in real time. On one side, it must be connected through interfaces to the external sources of the infrastructural and operational data, and from the other side, to the companies using EPLOS. This is the condition to get a useful and efficient tool offering current and reliable data on the European logistics system.

The EPLOS database is modular. Each of the modules is responsible for different types of information relating to the thematic areas. An integrated EPLOS database is composed of the following sub-databases: database of logistic companies, database of non-intermodal transhipment terminals , database of intermodal transhipment terminals, database of warehouse type logistics facilities, database of the sections of the road network, database of gas stations, database of car washes, database of parking lots, database of the sections of the railway network, database of railway stations, database of loading points, database of inland waterway network sections, database of inland water ports and transhipment quays, database of airports.

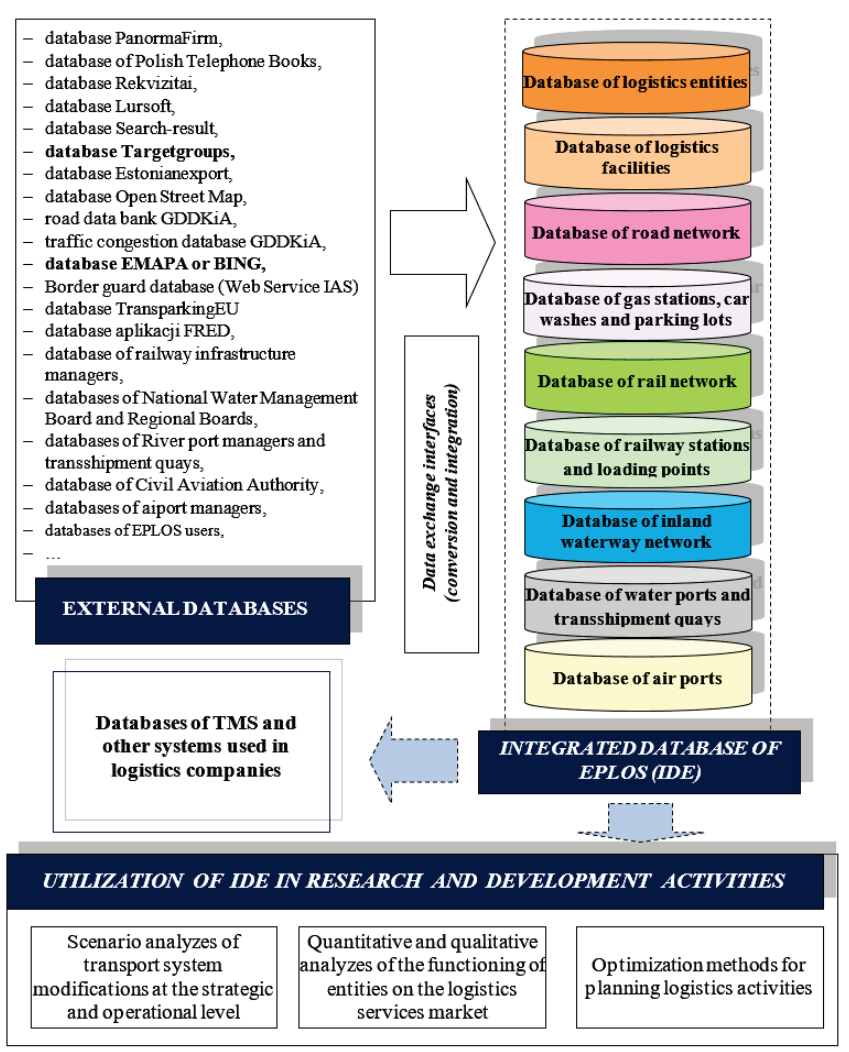

Figure 1 Structure of the database and module integration in EPLOS

The EPLOS system also includes the input and output interface modules, internal interfaces and graphical interfaces. The system is also equipped with a digital map module with its own database combined with other EPLOS databases. Schematically, all elements of an EPLOS integrated database are shown in Fig. 1 (data sources available only in the commercial version of EPLOS are bolded).

Each element of the integrated database is associated with other elements by strict rules. Integration of system components with external databases requires the integration of modules and the conversion of data to the required form. Data is standardized before it is incorporated into the EPLOS system. All data in the EPLOS databases undergoes feedback. This means that the results of data analysis and their use can later supplement the database and be the basis for further research.

The primary goal of the database is to support the operational activities of the companies operating on the logistics services market and other industrial markets that take advantage of transport. The secondary goal is to have a database for studies and analyses at different levels of detail. Depending on the needs, the database can be used for an analysis of the logistics market and its functioning, a simulation of the impact that the modification of the transport network will have on the logistics business, or an assessment of transport and finally, for an analysis of the handling and storage potential that regions can offer to the business.

Universality and comprehensiveness of the database also make it usable in other software packages. It can be built into applications by extending the EPLOS system for financial, analytical and optimization tools.

All databases included in EPLOS are associated with other databases by specific relations. The core database is the one which contains the following information about logistics companies:

- numbers and names of companies,

- parent entity numbers,

- headquarters' addresses and geographical coordinates,

- types of business, areas of activity and scope of services,

- opening days and hours,

- website addresses,

- contact details (e-mail addresses, phone numbers),

- disposed logistics facilities (numbers of nods in the transport/logistics network and the length of owned transport networks).

Accordingly, each logistics entity in the EPLOS database can be defined by specific logistics facilities (e.g. warehouses, transhipment terminals) that are managed by this entity. Databases on facilities contain additional information:

- number of the node in the transport network, its name and geographical coordinates,

- type of the node in the transport network (e.g. intermodal transport terminal),

- transport mode and transport means to be served in,

- opening hours,

- operator data,

- information on the customer service,

- information on the operating station,

- terminal availability (open, contractual), 
- $\quad$ scope of performed services,

- available loading devices,

- $\quad$ length of the loading front (m),

- types of cargo handled,

- $\quad$ maximum total weight of transport means $(\mathrm{kg})$,

- maximum length of supported transport means (m),

- daily throughput (transport means/day),

- $\quad$ total storage area $\left(\mathrm{m}^{2}\right)$,

- available storage area $\left(\mathrm{m}^{2}\right)$,

- $\quad$ pallet storage capacity (PAL),

- $\quad$ available pallet storage capacity (PAL),

- container storage capacity (TEU),

- $\quad$ available container storage capacity (TEU).

Databases for individual transport networks collect information on:

- number and name of the section of the transport network,

- infrastructure manager (number and name from the logistic entity database),

- numbers of the start and end node of the section in the transport network,

- mode of transport,

- category of road / type of railway line / type of waterway,

- types of vehicles allowed for movement,

- road tolls / fees for access to the railway infrastructure,

- traffic directions,

- technical class of the road / class of the railway line / navigability class of the waterway,

- type of road surface / type of railway track,

- number of lanes / tracks in the main direction and in the opposite direction,

- $\quad$ road section length $(\mathrm{m})$,

- $\quad$ speed limit on the road or the maximum speed on the railway / waterway $(\mathrm{km} / \mathrm{h})$,

- restrictions on the permissible total weight of transport means $(\mathrm{t})$,

- $\quad$ restrictions on the actual total weight of transport means / gross weight of the train $(\mathrm{t})$,

- hours of tonnage restrictions,

- $\quad$ permissible axle loads of transport means ( $\mathrm{kN} / \mathrm{axle})$,

- train / ship length (m),

- restrictions on the vertical gauge / permissible height of ships (m),

- $\quad$ restrictions on the horizontal gauge / permissible width of ships (m),

- $\quad$ minimum clearance under bridges over Great Navigable Water $(\mathrm{m})$,

- $\quad$ navigable route width $(\mathrm{m})$,

- transit depth (m),

- traffic restrictions on transport means carrying ADR materials,

- restrictions on transport means due to exhaust emissions,

- $\quad$ longitudinal slope of the road (tenth of percent),

- road technical condition,

- current speeds in the main direction and the opposite direction,

- $\quad$ traffic incidents (description and location of an incident),

- unplanned outages / temporary closures,

- current water level $(\mathrm{cm})$.
More detailed information on the solutions adopted for the EPLOS databases describing road and rail networks, as well as on logistics facilities, are presented in $[13,22,23]$.

\section{CONCLUSIONS}

The effectiveness of logistics processes is conditioned by the access to complete and up-to-date information on the logistics infrastructure, logistics companies and their contractors. This data often come from various sources and in most cases require a manual search and time-consuming processing. The EPLOS project responds to these issues. The outcome of the project is an IT system feeding logistics entities with reliable and actual data obtained from various, but validated sources.

Research on the possibility of an automated data collection and update from the existing sources show that such a collection is now not possible or is significantly limited. This is confirmed by the results of a survey carried out on logistic companies and market representatives. The respondents pointed out that almost all relevant and important logistics information must be gained manually and then also manually entered into their systems. As a consequence, companies engage significant resources in data acquisition and processing and they incur additional costs as a result of the poor-quality data or lack in information.

Limited or closed access to data might significantly limit and delay benefits from any IT solution designed to plan and manage logistics processes in the company. In a worst-case scenario, such implementation can be unjustified or used only partly.

This observation shows that centralized expenditures on the access to logistics and transport infrastructure data is a rational solution. Logistics companies save time and have a guarantee that data are of adequate quality and form. Thus, the users' benefits from the access to the EPLOS databases are indisputable. In some cases, users will be obliged to provide data about their facilities and services to EPLOS. This data can be entered manually or available via interfaces between EPLOS and their internal database. Such an exchange will increase the quality of the entire system.

EPLOS will be very beneficial for companies implementing new IT solutions such as the Transport Management System, Warehouse Management System, Enterprise Resource Planning or specialized Supply Chain Management Systems, Distribution Resource Planning or Advanced Planning Systems. They will be able to feed their databases with information about market participants and their actual or potential partners. This information will be regularly updated by EPLOS.

The big advantage of the EPLOS system is the up-to-date information on transport network parameters, loading points and costs of their use. Such data is necessary for the planning of transport processes, especially over long distances and when using multiple modes of transport. Inquiries to the EPLOS system may relate to the variants of transport routes for a given mode of transport or for a specific type of load/material.

To summarize, constantly updated EPLOS databases can be crucial for logistics companies to make transport, storage and handling more effective and faster. It consequently leads 
to economic benefits. There is a high potential for developing EPLOS by adding decision supporting models which cover various areas of material flow management and supply chain configuration to the system (see [24-29]). The EPLOS system can be a significant support for macroeconomic traffic models, such as [30-32].

\section{Acknowledgments}

This study is the result of work carried out as part of the EPLOS (European Portal of Logistics Services) project under the EUREKA initiative funded by the National Centre for Research and Development.

\section{Notice}

The paper will be presented at MOTSP 2020 International Conference Management of Technology - Step to Sustainable Production, which will take place from $30^{\text {th }}$ September $-2^{\text {nd }}$ October 2020 in Bol, island Brač (Croatia). The paper will not be published anywhere else.

\section{REFERENCES}

[1] Babaian, T. \& Lucas, W. (2013). Modeling Data for Enterprise Systems with Memories. Journal of Database Management, 24(2), 1-12. https://doi.org/10.4018/jdm.2013040101

[2] Elmasri, R. \& Navathe, S. B. (2016). Fundamentals of Database Systems, the $7^{\text {th }}$ Editions, Pearson Education India.

[3] Jachimowski, R., Gołebiowski, P., \& Pyza D., (2016). Kształtowanie baz danych dla wizualizacji obiektów magazynowych w 3D. Oficyna Wydawnicza Politechniki Warszawskiej.

[4] Jacyna, M., Gołębiowski, P., Szczepański, E., \& Wasiak, M. (2017). Efficacy of Data Security in Managing the Database of SIMMAG 3D System. Procedia Engineering, 187, 526-531. https://doi.org/10.1016/j.proeng.2017.04.410

[5] Jacyna, M., Wasiak, M., \& Bobiński, A. (2017). SIMMAG3D as a tool for designing of storage facilities in 3D. Archives of Transport, 42(2), 25-38. https://doi.org/10.5604/01.3001.0010.0525

[6] Jacyna, M., Wasiak, M. (ed.), et al., (2017). Warehouse designing and modeling with $3 \mathrm{D}$ visualization support. Index Copernicus International, Warsaw.

[7] McFadden, F. R., Hoffer, J. A., \& Prescott, M. B. (1998). Modern database management. Reading, MA: AddisonWesley.

[8] Semenov, I., Filina-Dawidowicz, L., \& Trojanowski, P. (2019). Integrated approach to information analysis for planning the transport of sensitive cargo. Archives of Transport, 51(3), 6576. https://doi.org/10.5604/01.3001.0013.6163

[9] Tang, Y. \& Zhang, W. (2016). Computer-aided model construction and database design of railway yard information. Archives of Transport, 38(2), 71-78. https://doi.org/10.5604/08669546.1218799

[10] Arliansyah, J., Utama, Y., Wijayanti, M. A., Gusti, R., \& Arifianto. (2017). Analysis and design of road and bridge infrastructure database using online system. MATEC Web of Conferences, 138, 07011.

https://doi.org/10.1051/matecconf/201713807011

[11] Connolly, T. M. \& Begg, C. E. (2015). Database Systems: A Practical Approach to Design, Implementation and Management, the $6^{\text {th }}$ Edition, Harlow, Essex, England: Pearson Education Limited.
[12] Dong, Y. \& Goh, A. (1998). An intelligent database for engineering applications. Artificial Intelligence in Engineering, 12(1-2), 1-14. https://doi.org/10.1016/S0954-1810(96)00033-7

[13] Jacyna M., et al. (2019). The Concept of EPOS Database of the Transport Infrastructure. w: $23^{\text {rd }}$ international scientific conference Transport Means 2019 Sustainability: Research and Solutions Proceedings $23^{\text {rd }}$ International Scientific Conference / Kersys Robertas (ed.), TRANSPORT MEANS, Publishing House "Technologija", 1250-1255.

[14] Pyza, D., et al. (2017). Database Security in Terms of Modeling and Visualization of Warehouse Objects in 3D Using System SIMMAG3D. Proceedings of $21^{\text {st }}$ International Scientific Conference Transport Means 2017. Juodkrante, Lithuania: Kaunas University of Technology, 814-818.

[15] Vossen, G. (1991). Data models, database languages and database management systems. Choice Reviews Online, 29(02). https://doi.org/10.5860/CHOICE.29-0950

[16] Ziems, M., Rottensteiner, F., \& Heipke, C. (2017). Verification of road databases using multiple road models. ISPRS Journal of Photogrammetry and Remote Sensing, 130, 44-62. https://doi.org/10.1016/j.isprsjprs.2017.05.005

[17] Żak, J., Jachimowski, R., Gołębiowski, P., \& Szczepański, E. (2017). Relational character of the data in the context of functional modules of the system SIMMAG 3D. CLC 2016: Carpathian Logistics Congress - Congress Proceedings. Edition $1^{\text {st }}$. Ostrava: Tanger Ltd., 700-705.

[18] Jachimowski, R., Gołębiowski, P., Izdebski, M., Pyza, D., \& Szczepański, E. (2017). Designing and efficiency of database for simulation of processes in systems. Case study for the simulation of warehouse processes. Archives of Transport, 41(1), 31-42. https://doi.org/10.5604/01.3001.0009.7380

[19] Benedikt, M., Bourhis, P., \& Ley, C. (2015). Analysis of Schemas with Access Restrictions. ACM Transactions on Database Systems, 40(1), 1-46. https://doi.org/10.1145/2699500

[20] Cannan, S. J., \& Otten, G. M. A. (1993). SQL - The standard handbook. London: McGraw-Hill.

[21] Hasselbring, W. (2000). Information system integration. Communications of the ACM, 43(6), 32-38. https://doi.org/10.1145/336460.336472

[22] Wasiak M., et al. (2019). Concept of EPLOS database of logistics facilities. w: $23^{\text {rd }}$ international scientific conference Transport Means 2019 Sustainability: Research and Solutions Proceedings $23^{\text {rd }}$ International Scientific Conference / Kersys Robertas (red.), TRANSPORT MEANS, Publishing House "Technologija", 1317-1322.

[23] Wasiak M., Szczepański E., Gołębiowski P., \& Leleń P. (2019). Struktura baz danych sytemu EPLOS o infrastrukturze transportu drogowego oraz kolejowego, Prace Naukowe Politechniki Warszawskiej. Transport, 125, 191-204.

[24] Chai, H., He, R., Jia, X., Ma, Ch., \& Dai C., (2018). Generalized route planning approach for hazardous materials transportation with equity consideration. Archives of Transport, 46(2), 33-46. https://doi.org/10.5604/01.3001.0012.2101

[25] Izdebski, M., \& Jacyna, M., (2018). The organization of municipal waste collection: The decision model. Rocznik Ochrona Srodowiska, Tom 20(1), 919-933,

[26] Jacyna, M., Izdebski, M., Szczepański, E., \& Gołda, P., (2018). The task assignment of vehicles for a production company. Symmetry, 10(551), 1-19. https://doi.org/10.3390/sym10110551

[27] Leleń, P. \& Wasiak, M., (2019). The model of selecting multimodal technologies for the transport of perishable products. Archives of Transport, 50(2), 17-33. https://doi.org/10.5604/01.3001.0013.557 
[28] Szczepański, E., Jachimowski, R., Izdebski, M., \& JacynaGołda, I., (2019). Warehouse location problem in supply chain designing: a simulation analysis. Archives of Transport, 50(2), 101-110. https://doi.org/10.5604/01.3001.0013.5752

[29] Wasiak, M., Jacyna, M., Lewczuk, K., \& Szczepański, E., (2017). The method for evaluation of efficiency of the concept of centrally managed distribution in cities. Transport, 32(4), 348-357. https://doi.org/10.3846/16484142.2017.1345005

[30] Jacyna, M. (2012), The model of national logistics system in aspect of cargo flow rationalizations. International Conference on Industrial Logistics. ICIL 2012 - Conference Proceedings, 196-203.

[31] Jacyna M., Basiewicz T., \& Gołaszewski A., (2012). Parametry infrastruktury transportu dla tworzenia modelu systemu logistycznego w Polsce. Problemy Kolejnictwa, 154, 5-26.

[32] Jacyna, M., Wasiak, M., Lewczuk, K., \& Kłodawski, M. (2014). Simulation model of transport system of Poland as a tool for developing sustainable transport. Archives of Transport, 31(3), 23-35.

https://doi.org/10.5604/08669546.1146982

\section{Authors' contacts:}

Mariusz Wasiak, Associate Professor, PhD (Eng.)

(Corresponding author)

Faculty of Transport, Warsaw University of Technology, Koszykowa 75, room 363, 00-662 Warsaw, Poland

mwa@wt.pw.edu.pl

Michał Kłodawski, Associate Professor, PhD (Eng.)

Faculty of Transport, Warsaw University of Technology, Koszykowa 75, room 366, 00-662 Warsaw, Poland

mkloda@wt.pw.edu.pl

Konrad Lewczuk, Associate Professor, PhD (Eng.)

Faculty of Transport, Warsaw University of Technology, Koszykowa 75, room 366, 00-662 Warsaw, Poland

konrad.lewczuk@pw.edu.pl

\section{Piotr Klimek}

OLTIS Polska Sp. z 0. o.

Króla Kazimierza Wielkiego 21/203A, 32-300 Olkusz, Poland

info@oltis.pl; www.oltis.pl

Emilian Szczepański, Associate Professor, PhD (Eng.) Faculty of Transport, Warsaw University of Technology, Koszykowa 75, room 367, 00-662 Warsaw, Poland

eszczepanski@wt.pw.edu.pl 